\title{
Acil Serviste Spontan Pnömotoraks Tanısı Alan Hastaların Demografik Verilerinin Retrospektif Olarak Değerlendirilmesi
}

\section{A Retrospective Evaluation of the Demographic Characteristics of Patients Diagnosed with Spontaneous Pneumothorax}

\author{
Canan Akman ${ }^{1}$, Murat Çetin ${ }^{2}$ \\ ${ }^{1}$ Çanakkale Onsekiz Mart Üniversitesi, Tip Fakültesi, Acil Tip Anabilim Dalı, Çanakkale, Türkiye \\ Yazı̨̧ma Adresi / Correspondence: \\ Murat Çetin \\ İzmir Tinaztepe Üniversitesi Aydoğdu, 1267/1. Sk. No:4, 35400 Buca/İzmir \\ T: $+905358964252 \quad$ E-mail : muratcetinn@gmail.com \\ Geliṣ Tarihi / Received : 05.09.2020 Kabul Tarihi / Accepted : 27.12.2020 \\ Orcid : \\ Canan Akman https://orcid.org/0000-0002-3427-5649 \\ Murat Çetin https://orcid.org/0000-0002-0667-7966 \\ ( Sakarya Tip Dergisi / Sakarya Med J 2021, 11(1):9-14) DOI: 10.31832/ smj.790812
}

${ }^{2}$ İzmir Tinaztepe Üniversitesi, Sağllk Hizmetleri Meslek Yüksekokulu, İlk ve Acil Yardım Bölümü, İzmir, Türkiye

\footnotetext{
$\ddot{\mathrm{Oz}}$

Amac Pnömotoraks, plevral boșlukta hava bulunmasıılır. Pnömotoraks tanılarııın yarıdan fazlası herhangi bir travma durumu söz konusu olmadan ortaya çıkmaktadır. Bu durum spontan pnömotoraks (SP) adını almaktadır. Aynı zamanda pnömotoraks vakaları ile acil serviste sıkça karşılaşıımaktadır. Tanı ve tedavisinin acil olarak yapııması gereken bir plevra hastalı̆̆ıdır. Bu çalışmada acil servise başvuran SP hastalarının demografik özellikleri, risk faktörleri, klinik özellikleri, tanı ve tedavi yaklașımlarııın farkındalığının ortaya konulması amaçlanmışıır.

Gereç ve Ocak 2018-Haziran 2020 tarihleri arasında Canakkale Onsekiz Mart Üniversitesi Tip Fakültesi acil servisine basvuran SP tanısı alan hastalar retrospektif olarak tek merkezli Yöntem incelenmiștir. Hastalarda yaș, cinsiyet, acil servise geliș șekilleri, şikayetleri, altta yatan hastalık durumları, sigara öyküsü, daha önce pnömotoraks șikayeti varlığı, nüks ve sayısı, fizik muayene bulguları, eşlik eden durumlar, tansiyon pnömotoraks varlı̆̆ı, tüp torakostomi tedavisi ve tedavinin sonuçları belirlenmiş̧tir.

Bulgular Acil servise başvurup SP tanısı alan 53 hasta çalışmaya dahil edildi. Hastaların \%92,5’ $\mathrm{i}(\mathrm{n}=49$ ) erkektir. \%92,5’ine ( $\mathrm{n}=49$ ) tüp torakostomi işlemi uygulanmıştır. Bu hastaların \%84,9’u ( $\mathrm{n}=45)$ gögüs cerrahi servisine, \%11,3’ü ( $\mathrm{n}=6)$ yoğun bakıma ve \%2’si $(\mathrm{n}=3,8)$ dış merkeze sevk edilmiştir. Hastaların \%88,7’si ( $\mathrm{n}=47)$ şifa ile taburcu olmuş̧tur.

Sonuç Spontan pnömotoraks zamanında müdahale edilmediğinde hayati tehlike olușturabilecek bir klinik durumdur.

Anahtar Spontan pnömotoraks; Acil servis; Tüp torakostomi

Kelimeler

Abstract

Objective Pneumothorax is the presence of air in the pleural cavity. More than half of pneumothorax cases occur withou tany preceding trauma, and are referredto as spontaneous pneumothorax (SP). $S P$ is also a commonly encountered clinical condition in emergency departments It is a pleural disease that requires urgent diagnosis and treatment. The purpose of this study is to determine the demographic features, risk factors, clinical features, as well as, awareness of approach to treatment in patients admitted to the emergency department with SP.

Materials This retrospective, single-center study was conducted among patients diagnosed with SP in the Emergency department of Canakkale Onsekiz Mart University between January 2018-June and methods 2020. Age, gender, types of admission to the emergency room, complaints, underlying disease conditions, smoking history, presence of previous pneumothorax complaints, recurrence and number, physical examination findings, accompanying conditions, presence of tension pneumothorax, tube thoracostomy treatment and the results of the treatment were determined.

Results 53 Patients diagnosed with SP after admittance to the emergency department were included in the study; with $92,5 \%$ ( $n=49)$ male patients. $92,5 \%$ ( $n=49$ ) of these patients underwent tube thoracostomy. $84.9 \%(n=45)$ of these patients were referred to the chest surgery service, $11.3 \%(n=6)$ to intensive care and $2 \%(n=3.8)$ to an external center. $88.7 \%$ ( $n=47)$ of the patients were discharged with recovery.

Conclusion Spontaneous pneumothorax is likely a life-threatening clinical condition if not treated in time.

Keywords Spontaneous pneumothorax; Emergency department; Tube thoracostomy
} 


\section{GIIRIŞ}

Spontan pnömotoraks (SP), travma olmadan plevral boşlukta hava toplanması ve sonrasında buna eşlik eden akciğerin kollapsıdır. ${ }^{1,2}$ Sağlıklı bir bireyde bu durumun oluşması primer spontan pnömotoraks, altta yatan akciğer hastalığı söz konusu ise sekonder pnömotoraks olarak ifade edilmektedir. Spontan pnömotoraks risk faktörleri arasında erkek cinsiyet, sigara kullanılması, uzun boy, düşük vücut ağırlığı, altta yatan akciğer hastalığı yer almaktadır. ${ }^{3}$ Ani olarak görülen nefes darlığı, eşlik eden göğüs ağrısı, çarpıntı, prodüktif öksürük şikayeti görülebilmektedir. ${ }^{4}$ Fizik muayenenin yapılması tanısal olarak anlamlıdır. Spontan pnömotoraks, hastalarının yönetimi yakın gözlem ve oksijen tedavisi yanında konservatif yaklaşım olduğu gibi aspirasyon, perkütan kateter ile drenaj, tüp torakostomi, video toraskopik cerrahi, aksiler veya lateral torakotomi tedavilerini de içermektedir..$^{5-8}$

Çalışmamızda acil servise başvuran spontan pnömotoraks hastalarının demografik özellikleri, risk faktörleri, klinik özellikleri, tanı ve tedavi yaklaşımları açısından tecrübelerimizi paylaşmayı amaçladık.

\section{GEREÇ ve YÖNTEMLER}

Çanakkale Onsekiz Mart Üniversitesi Tip Fakültesi acil servisinde retrospektif olarak planlanan tek merkezli çalışmaya Çanakkale Onsekiz Mart Üniversitesi Girişimsel Olmayan Klinik Araştırmalar Etik Kurulu 01.07.2020 tarihli 2011-KAEK-27/2020-E.2000075170 nolu çalışma 2020-09 sayılı onay alındıktan sonra başlanmıştır. Elektronik kayıt sistemi üzerinden Ocak 2018-Haziran 2020 tarihleri arasında başvuran ve spontan pnömotoraks tanısı alan hastalar alınmıştır. Hastane otomasyon sisteminde dosyasına ulaşamadığımız ve 18 yaş altı hastalar çalışmaya alınmamıştır.

Verilerin istatistiksel olarak olarak değerlendirilmesinde SPSS 20.0 kullanılmıştır. Tanımlayıcı verilerin sunumunda sayı, yüzde, ortalama, standart sapma, ortanca, minimum, maksimum kullanılmıştır. Nominal verilerin karşılaştırıl- masında ise Kikare Testi kullanılmıştır. p $<0.05$ istatistiksel olarak anlamlı kabul edilmiştir.

\section{BULGULAR}

Çalışmaya 53 hasta dahil edildi. Hastaların yaş ortalaması 50,5 $\pm 24,7$ y1l, ortancas 158,0 y1ld1. (min:18,0-maks:90,0). Hastaların \%92,5'i (n=49) erkek, \%7,5'i (n=4) kadındı. Hastaların acil servise başvurusuna bakıldığında; 26'sı $(\% 49,1) 112$ Acil ambulansı ile 27'si $(\% 50,9)$ ayaktan başvuru şeklindeydi. Hastaların 34'ü $(\% 64,2)$ il merkezinden ve 19 ’u $(\% 35,8)$ merkeze bağlı ilçelerden gelmişti.

Çalışmaya alınan hastaların 29'unda $(\% 54,7)$ nefes darlığı en sık acil servis başvuru şikayeti olarak karşımıza çıkmaktaydı. Diğer şikayetler sırası ile göğüs ağrısı, çarpıntı ve öksürüktü. Fizik muayenede 34'ünde $(\% 64,2)$ tek taraf$l_{1}$ solunum seslerinin azaldığ servise başvurduğunda 49'unda $(\% 92,5)$ eşlik eden patoloji yoktu. Üç hastada $(\% 5,7)$ pnömomediastinum varken, 1 hastada $(\% 1,8)$ akut böbrek yetmezliği tespit edildi.

Çalışmaya alınan hastaların 8'sinde $(\% 15,1)$ daha önceden pnömotoraks öyküsü vardı. İki hastanın nüks sayısı 3 $(\% 3,8)$ olarak tespit edildi. Otuz sekiz hasta $(\% 71,7)$ sigara içicisiydi. Çalışmamızdaki hastaların 7’sinde (\%28) kronik obstrüktif akciğer hastalığı (KOAH), l'inde (\%4) diabetes mellitus (DM) ve hipertansiyon, 1'inde (\%4) hipertansiyon, 8’sinde (\%32) pnömoni, 5 'inde (\%20) akciğer kanseri, l'inde (\%4) KOAH ve koroner arter hastalığı birlikteliği, 2 'sinde (\%8) KOAH ve pnömoni hikayesi mevcuttu.

Ayrıca hastaların 2'sinde $(\% 3,8)$ tansiyon pnömotoraks varlığ1 görüldü. Hastaların 49'una $(\% 92,5)$ tüp torakostomi uygulanırken, 6’sı $(\% 11,3)$ yoğun bakıma, 45’i $(\% 84,9)$ gögüs cerrahi servisine yatırıldı. Ancak $2(\% 3,8)$ hasta başka bir hastaneye sevk edildi. Takiplerinde hastaların; 47'si $(\% 88,7)$ taburcu, 6’sı (\%11,3) eksitus olmuştur. 
Sakarya Tip Dergisi 2021;11(1):9-14

AKMAN ve Ark., Spontan Pnömotoraks Hastalarının Demografik Verileri

\begin{tabular}{|c|c|c|c|}
\hline \multicolumn{2}{|l|}{ Değisşkenler } & $\mathbf{n}$ & $\%$ \\
\hline \multirow{2}{*}{ Hastaların geliş şekli } & 112 Ambulans & 26 & 49,1 \\
\hline & Ayaktan gelen & 27 & 50,9 \\
\hline \multirow{2}{*}{ Nereden geldiği } & Merkez & 34 & 64,2 \\
\hline & İlçe & 19 & 35,8 \\
\hline \multirow{5}{*}{ Geliș şikayeti } & Nefes darlığ 1 & 29 & 54,7 \\
\hline & Göğüs ağrısı & 14 & 26,4 \\
\hline & Nefes darlığı ve göğüs ağrısı & 8 & 15,1 \\
\hline & Nefes darlı̆̆ı 1 ve çarpıntı & 1 & 1,9 \\
\hline & Çarpıntı & 1 & 1,9 \\
\hline \multirow{2}{*}{ Altta yatan hastalık varlığı } & Var & 25 & 47,2 \\
\hline & Yok & 28 & 52,8 \\
\hline \multirow{7}{*}{ Hastalıklar } & $\mathrm{KOAH}$ & 7 & 28,0 \\
\hline & DM ve Hipertansiyon & 1 & 4,0 \\
\hline & Hipertansiyon & 1 & 4,0 \\
\hline & Pnömoni & 8 & 32,0 \\
\hline & Akciğer kanseri & 5 & 20,0 \\
\hline & KOAH ve Koroner arter hastalığı & 1 & 4,0 \\
\hline & KOAH ve Pnömoni & 2 & 8,0 \\
\hline
\end{tabular}

\begin{tabular}{|l|c|c|c|}
\hline \multicolumn{2}{|l|}{ Tablo 2. Acil servise başvurup spontan pnömotoraks tanısı alan olguların muayene, tedavi ve son durum bilgileri } \\
\hline Değişkenler & Tek taraflı solunum seslerinin azalması & 34 & n \\
\hline \multirow{3}{*}{ Fizik muayene } & Tek taraflı solunum seslerinin yokluğu & 19 & 64,2 \\
\hline \multirow{3}{*}{ Eşlik eden durumlar } & Yok & 49 & 35,8 \\
\cline { 2 - 4 } & Pnömomediastinum & 3 & 92,5 \\
\cline { 2 - 4 } & Akut böbrek yetmezliği & 1 & 5,7 \\
\hline \multirow{3}{*}{ Tansiyon pnömotoraks varlı̆̆ı } & Var & 2 & 1,8 \\
\hline \multirow{3}{*}{ Tüp torakostomi uygulanması } & Yok & 51 & 3,8 \\
\hline \multirow{3}{*}{ Acil servisten sonlanımı } & Var & 49 & 96,2 \\
\cline { 2 - 4 } & Yok & 4 & 92,5 \\
\cline { 2 - 4 } & Yoğun bakım & 6 & 7,5 \\
\hline \multirow{2}{*}{ Hastaneden sonlanımı } & Servis yatış & 45 & 11,3 \\
\cline { 2 - 4 } & Sevk & 2 & 84,9 \\
\cline { 2 - 4 } & Taburcu & 47 & 3,8 \\
\cline { 2 - 4 } & Eksitus & 6 & 88,7 \\
\hline
\end{tabular}

Tablo 2. Acil servise başvurup spontan pnömotoraks tanısı alan olguların muayene, tedavi ve son durum bilgileri

\begin{tabular}{|l|l|c|c|c|}
\hline \multicolumn{2}{|l|}{ Değişkenler } & Nüks var n (\%) & Nüks yok n (\%) & \multirow{2}{*}{$\mathrm{p}$} \\
\hline \multirow{2}{*}{ Sigara kullanımı } & Var & $5(13,2)$ & $33(86,8)$ & \multirow{2}{*}{0,673} \\
\cline { 2 - 4 } & Yok & $3(20,0)$ & $12(80,0)$ & \\
\hline \multirow{2}{*}{ Kronik hastalık } & Var & $2(8,0)$ & $23(92,0)$ & \multirow{2}{*}{0,256} \\
\cline { 2 - 4 } & Yok & $6(21,4)$ & $22(78,6)$ & \\
\hline
\end{tabular}




\section{TARTIŞMA}

Literatüre bakıldığında, Hallifax ve arkadaşlarının yaptığı bir çalışmada da spontan pnömotoraksın erkeklerde daha fazla olduğu görülmektedir. ${ }^{9}$ Aynı şekilde başka bir çalışmada ise erkeklerde, kadın cinsiyete göre 6 kat daha sık olarak spontan pnömotoraks görüldüğü gösterilmiştir. ${ }^{10}$ Çalışmamızda da hastaların 49 (\%92,5)'u erkekti. Sigara içilmesinin spontan pnömotoraks için bir risk faktörü olduğu ifade edilmiştir. ${ }^{1}$ Yapılan bir çalışmada sigara içen hasta grubunda, içmeyenlere göre spontan pnömotoraksın 20 kat daha fazla olduğu gösterilmiştir. ${ }^{11}$ Göğüs cerrahlar1nın yaptığı bir çalışmada ise sigara içiminin yaygın olarak görüldüğü ülkelerde spontan pnömotoraksın sık görülen bir hastalık olduğu bildirilmiştir. ${ }^{12}$ Çalışmamızda spontan pnömotoraksı olan hastalarımızın \%71.7'sinde sigara içme öyküsü mevcuttur. Spontan pnömotoraks tanısı almış olgularımızın \%52,8'inde herhangi bir hastalık mevcut değildir. Hastalığı olanların, \%32'sinde akciğer enfeksiyonu, \%28'inde kronik obstrüktif akciğer hastalığı, \%20'sinde akciğer kanseri mevcuttur. Literatürde spontan pnömotoraksın akciğerde altta yatan bir nedenden kaynaklandığ ve kronik akciğer hastalıklarının bunun en sık nedenleri arasında olduğu belirtilmektedir., ${ }^{6,11}$

Nüks oranı ise spontan pnömotorakslarda \%25-54 olarak literatürde verilmektedir. ${ }^{1}$ Çelik ve arkadaşlarının yaptığ bir çalışmada ise nüks oranı $\% 17$ olarak verilmiştir. ${ }^{3}$ Çalışmamızda ise nüks oranı $\% 15,1$ olarak bulunmuştur. Nüks sayısı olarak değerlendirildiğinde ise 2 nükse sahip hasta oranı $\% 7,5$ dur. Spontan pnömotoraks tanısında hastanın şikayetleri ve yapılan fizik muayene çok değerlidir. Hastaların başlıca şikayetleri göğüs ağrısı, nefes darlığı, çarpınt1, terleme, hipotansiyon ve siyanoz olabilmektedir., ${ }^{6,13}$ Çelik ve arkadaşlarının yaptığı bir çalışmada hastaların en sık başvuru şikayeti nefes darlığı olarak verilmiştir. ${ }^{3}$ Diğer bir çalışmada ise ani olan nefes darlığı ve göğüs ağrısı en sık hastaneye başvuru şikayeti olarak verilmiştir. ${ }^{1}$ Hastalar sıklıkla göğüs ağrısı ve nefes darlığı gibi şikayetlerle başvuru yapmaktadır. ${ }^{17}$
Çalışmamızda hastaların acil servise başvurusunda en sık görülen iki şikayet \%54,7 nefes darlığı, \%26,4 göğüs ağrısıdır. Pnömotoraks hastalarında bir anda oluşan hipotansiyon, takipne, taşikardi ve siyanoz durumu tansiyon pnömotoraks açısından uyarıcı işaretlerdir. Ancak spontan pnömotoraks vakalarında tansiyon pnömotoraks görülmesi nadir olarak karşımıza çıkmakla birlikte bilinmelidir ki tansiyon pnömotoraks tanısı radyolojik değil, klinik bir tanıdır. Bu durum çok acil müdahaleyi gerektirmektedir. ${ }^{1,16}$ Spontan pnömotoraksın tansiyon pnömotoraksa dönüşmesi \%1-5 arasında bildirilmektedir. ${ }^{17}$ Çalışmamızda tansiyon pnömotoraks varlığ $1 \% 3,8$ olarak bulunmuş, nadir olarak görüldügü sonucuna katkı sağlamış ve bu olgularda intraplevral havayı boşaltmak ve mediastinal baskıyı azaltmak için acil tüp torakostomi uygulama yapılmıştır. ${ }^{18,19}$ Spontan pnömotoraks fizik bulgusu bazen sinsi bir hava yaratsa da genelde karakteristiktir. Pnömotoraksın olduğu tarafta solunum seslerinin azalması ile kendini göstermektedir. ${ }^{20}$ Hastalar solunum seslerinin azalmasından, solunum yetmezliğine kadar giden değişken bir klinik tablo ile karşımıza çıkabilmektedir. Spontan pnömotoraksın tedavisindeki esas amaç; plevral aralıktaki havayı boşaltmak, akciğerin ekspansiyonu sağlamak aynı zamanda nüksün önlenmesine de yardımcı olmaktır. Böylece nefes darlığı ve göğüs ağrısı semptomları da giderilebilmektedir. $^{16,21} \mathrm{Bu}$ amaçla uygulanan yöntemler arasında gözlem ve oksijen verilmesi, aspirasyon, perkütan kateter ile drenaj, tüp torakostomi, video ile toraskopik cerrahi, torakotomi yer almaktadır. ${ }^{22}$

Çalışmamızda acil servise gelen hastalara tüp torakostomi tedavisi \%92,5 oranında yapılmış ve diğer cerrahi tedavi yaklaşımlarına ihtiyaç duyulmamıştır. Yapılan çalışmalar göstermekte ki, sadece uygulanan tüp torakostomi işlemi büyük oranda tedaviye yeterli cevap verebilmektedir. Primer olarak tedavi yaklaşımı pnömotoraksın derecesine göre konservatif yaklaşım veya tüp torakostomidir. Çalışmamızda konservatif yaklaşım oranı \%7,5'dur. ${ }^{1,6}$ Acil serviste spontan pnömotoraks tanısı alan hastaların $\% 84,9^{\prime} \mathrm{u}$ tüp torakostomi işlemi uygulandıktan sonra göğüs cerrahi 
servisine yatırılmış, \%11,3'ü ise yoğun bakıma yatılmıştır. Spontan pnömotoraksa eşlik eden durumlara bakıldığında \%3 oranında pnömomediastinum görülmektedir. Spontan gelişen pnömomediastinum tablosu nadir olarak görülmekle birlikte, hastalarda gögüs ağrısı ve nefes darlığına neden olduğundan klinik tabloya eşlik edebileceği de düşünülmelidir. ${ }^{23}$

Sonuç olarak, Spontan pnömotoraks hastaları genellikle acil servise göğüs ağrısı, nefes darlığı şikayetleri ile başvurmaktadır. Fizik muayenede bu hastalarda solunum seslerinde azalma veya seslerin alınamaması en sık olarak görülmektedir. Bu hastaların yönetiminde tüp torakostomi altın standart olarak yerini hala korumaktadır. Bu hastaların ilk başvuru alanları olarak acil servisten başlayarak; takip ve tedavilerine devam edilmektedir.

Unutulmamalı ki zamanında acil müdahale edilmediğinde spontan pnömotoraks yaşamı tehdit eden klinik bir tablodur. Zamanında tanı konulması ile birlikte yapılan uygun tedavi ile mortalite ve morbidite azaltılabilmektedir.

Çalışma Çanakkale Onsekiz Mart Üniversitesi Girişimsel Olmayan Klinik Araştırmalar Etik Kurulu 01.07.2020 tarihli 2011-KAEK-27/2020-E.2000075170 sayılı onayı ile Helsinki Deklerasyonuna uyularak yapılmıştır. 
Sakarya Tip Dergisi 2021;11(1):9-14

AKMAN ve Ark., Spontan Pnömotoraks Hastalarının Demografik Verileri

\section{Kaynaklar}

1. Özkan S, Yazıcı Ü,Erkmen SȘ, Taștepe Aİ, Karaarslan K, Aydın S, Şahin MF. Spontan Pnömotoraksta Tedavi Yaklaşımlarımız: 48 Olgunun Değerlendirilmesi. Türkiye Acil Tip Dergisi - Turk J EmergMed 2011;11(1):20-24.

2. Durceylan E, İliklerden DM. Spontan Pnömotoraksta Klinik Deneyimlerimiz. Osmangazi Tip Dergisi. 2019; 41(2): 147-152.

3. Çelik B, Furtun K, Demir H, Yllmaz MA. Spontan pnömotorakslı olgularımızın klinik özellikleri. Gülhane Tip Dergisi 2009; 51: 71-74.

4. De Vries WC, Wolfe WG: The management of spontaneous pneumothorax in emphysema. Surg Clin North Am. 1981; 60:851.

5. Henry M, Arnold T, Harvey J. BTS guidelines for the management of spontaneous pneumothorax. Thorax 2003; 58: ii39-52.

6. Kuzucu A, Soysal Ö, Ulutaş H. Optimal timing for surgical treatment to prevent recurrence of spontaneous pneumothorax. Surg Today 2006; 36: 865-868.

7. Șengül AT, Büyükkarabacak BY, Yetim DT, Çelik B, Sürücü P, Başoğlu A. Spontan Pnömotoraksta Tedavi Seçenekleri. J Kartal TR 2014;25(1):27-33.

8. Ylldıran H, Şahinoğlu T. Devlet hizmet yükümlülüğü süresinde spontan pnömotorakslara yaklaşım. Ortadoğu Tip Dergisi 2019; 1: 1-5.

9. Hallifax JR, McKeown E, Sivakumar P et al. Ambulatory management of primary spontaneous pneumothorax: an open-label, randomised controlled trial. Lancet 2020;396:39-49.

10. Soysal S, Topaçoğlu H, İtil O et al. Acil Serviste Erişkin Spontan Pnömotorakslı Hastaların Özellikleri. Türkiye Acil Tip Dergisi 2005; 5(1): 14-17.

11. Eken KY, Güleç E, Atasoy S, Gücü A. Primer Spontan Pnömotoraksta Klinik Deneyimlerimiz. Akciğer Arşivi: 2003; 4: 138-140.

12. Karasu S, Tokat AO, Kısacık E, Çakmak H, Karakaya J, Aydın E, Gülhan E, Kaya S. Spontan Pnömotoraks: 260 Hastanin Analizi. J Clin Anal Med 2012;3(2): 174-7.
13. Tözüm H, Sarttekin E, Hoșgün D, Kul C, Erdem Ș. Her pnömotoraks, primer spontan pnömotoraks değildir. İzmir Göğüs Hastanesi Dergisi, Cilt XXV, Sayı 3, 2011

14. Fry WA, Paape K. Pneumothorax. In: Shields TW, LoCicero III J, Ponn RB, Rusch VW (eds). General Thoracic Surgery. 6th ed. Philadelphia: Lippincott Williams \& Wilkins, 2005: 794-805.

15. Beauchamp G, Ouellette D. Spontaneous pneumothorax and pneumomediastinum In: Pearson FG, Cooper JD, Deslauriers J (eds). Thoracic Surgery. 2nd ed. Philadelphia: Churchill Livingstone, 2002: 1195-1213.

16. Metin M. Pnömotoraks. Güncel Göğüs Hastalikları Serisi 2018; 6 (2): 7-15.

17. Leigh-Smith S, Harris T. Tension pneumothorax-time for a re-think? EmergMed J 2005 22: 8-16.

18. Kaneda H, Nakano T, Taniguchi Y, et al. Three-step management of pneumothorax: time for a re-think on initial management. Interact Cardiovasc Thorac Surg 2013; 16: 186-92

19. Chan SS. The role of simple aspiration in the management of primary spontaneous pneumothorax. J Emerg Med 2008; 34:131e8.

20. Miller A. Spontaneous pneumothorax. In: Light RW, Lee YCG, eds. Textbook of pleuraldiseases. 2nd edn. London: Arnold Press, 2008: 445-63.

21. De Leyn P, Lismonde M, Ninane V, Noppen M, Slabbynck H, Van Meerhaeghe A, et al. Guidelines Belgian Society of Pneumology. Guidelines on the management of spontaneous pneumothorax. ActaChirBelg 2005;105:265-7.

22. Tschopp JM, Rami-Porta R, Noppen M, Astoul P. Management of spontaneous pneumothorax: state of the art. Eur Respir J 2006;28:637-50.

23. Göktekin MÇ. Acil serviste spontan pnömomediastinum tanılı hastaların değerlendirilmesi. Cukurova Med J 2019;44(4):1155-1159.) 